\title{
ORIGEN DE LAS UNIVERSIDADES POPULARES
}

The Origins of 'Popular Universities'

Víctor M. Montes Martín*

\section{RESUMEN}

Las Universidades Populares son unas instituciones con más de un siglo de existencia que hunden sus raíces en los ideales de la revolución francesa. En diversos países europeos e iberoamericanos han sido uno de los apoyos de la educación popular o educación permanente, aun así, su aparición en la historia fue en diferentes momentos. Tampoco fue impulsada de la misma manera en cada lugar, pero sí se planteó con objetivos similares. Empleando una metodología histórico-comparado estudiaremos el origen de las Universidades Populares en diferentes regiones europeas; los modelos de génesis a estudiar serán: el de origen danés, el de origen francés y el de origen británico. Realizaremos un estudio descriptivo de los modelos de génesis, para más tarde establecer una comparación. Para establecer las semejanzas y diferencias entre todos ellos. El análisis de los resultados nos llevará a realizar las conclusiones.

PALABRAS CLAVE: Universidad Popular, Educación Popular, Educación no Formal, Educación Permanente, Sistemas Educativos, Educación de Adultos, Educación Internacional.

\section{ABSTRACT}

\footnotetext{
* Universidad de Sevilla (España).
} 
Popular Universities are among institutions with over a century of existence are rooted in the ideals of the French Revolution. In many European and Latin American countries have been one of the props of popular education or continuing education, yet their appearance in history was at different times. Nor was driven in the same way in each place, but I was raised with similar objectives. Using a historical and comparative methodology study the origin of the Popular Universities in different European regions; genesis models studied are: the Danish origin, French origin and of British origin. Will conduct a descriptive study of the genesis models, and later make a comparison. To establish the similarities and differences between them. The analysis of the results leads us to make conclusions.

KEY WORDS: Popular Universities, Popular Education, Educational Systems, Non-Formal Education, Lifelong Learning, Adult Education.

$* * * * *$

\section{INTRODUCCIÓN}

El estudio presentado nos obliga a una búsqueda bibliográfica de autores de finales del siglo XIX y principios del XX. Estos propondrán datos sobre la aparición de las Universidades Populares en Europa, y más específicamente en los tres países en los cuales nos centraremos: Dinamarca, Francia y Reino Unido.

Las Universidades Populares (UPs), según la Federación Española de Universidades Populares (FEUP), coordinan distintos tipos de acciones; el desarrollo cultural, la promoción de la participación social, la educación y la formación en distintas vertientes: lúdica, técnica, literaria, musical, de tradiciones, etc., dirigido a personas de todas las . a tales bienes, y a quienes, el fin de disfrutar aprendiendo, forma parte de sus propias inquietudes.

\section{JUSTIFICACIÓN}

Al realizar la revisión bibliográfica sobre el tema que nos ocupa, podemos observar la no existencia de una génesis institucional referente sobre las otras, lo cual, impide saber de dónde surge el movimiento y quienes lo impulsaron.

Por esto, entendemos que existe una necesidad por parte de la comunidad educativa y del público en general de saber de la existencia de estas instituciones, sus funciones y a los usuarios a los que están dirigidas, y como no, saber su historia y su aparición. 
Con este estudio procuramos satisfacer en gran parte la necesidad de conocer el origen de estas instituciones además de despejar las dudas sobre sus principales funciones y objetivos, además de conocer las carencias que buscaban solucionar sus primeros usuarios. Estos objetivos están recogidos por la FEUP (2000):

- Sensibilizar, motivar y facilitar el acceso de todos los ciudadanos y ciudadanas que lo deseen, a los bienes y servicios educativos, formativos y culturales.

- Potenciar, el desarrollo personal y colectivo de los participantes, favoreciendo la adquisición de conocimientos, la expresión creativa, la convivencia y la tolerancia.

- Fomentar la participación social, cultural, política y económica para la vertebración social.

- Contribuir a la actualización educativa y a la formación para el empleo.

- Impulsar las producciones culturales propias de las personas y grupos pertenecientes a la Universidad Popular y su difusión, como elemento fundamental del desarrollo cultural de la localidad.

- Promover la integración social a través de la educación y formación, realizando programas específicos con los grupos más desfavorecidos, para facilitar el acceso a los bienes sociales y culturales en condiciones de igualdad.

- Favorecer el desarrollo de una metodología que impulse la acción concertada y la colaboración de los distintos servicios y organizaciones socioculturales que confluyen en el territorio.

Para aclarar la elección de los tres países de estudio que compararemos a continuación, debemos advertir que después de una revisión bibliográfica previa y la consulta de estudios de diversos autores tales como Palacios Morini (1903); Buisson (1896); Neila Muñoz (1999); o García Morilla, González Rueda \& Catalán Romero (1999), señalan diversos movimientos en Dinamarca, Francia y Reino Unido, por consecuencia de diferentes situaciones históricas que comentaremos más adelante

\section{MARCO TEÓRICO}

La educación popular es apoyada por diversos autores como Freire (1977) o Barreiro (1979), que pretenden el desarrollo de las personas a través de procesos educativos como objetos del cambio social.

Un sector importante de la educación popular desde finales del siglo XIX, lo han ocupado las UPs. La historia de estas instituciones repetidamente está ligada al avance democrático de los ciudadanos a nivel local. Nos referimos a estas instituciones como organismos que apoyan el cambio social y el desarrollo crítico del individuo. Estas UPs se formaron en torno al interés de desarrollo de estrategias socioculturales, aplicando una metodología activa, participativa y pluralista, posibilitando la educación continua, 
satisfaciendo así las necesidades básicas de aprendizaje a la población (Gallardo et al., 2007).

Como podemos observar en Buisson (1896) y en Palacios Morini (1903), las primeras señales de estas organizaciones se dan en Reino Unido y a continuación en Francia, pero según nos indica el informe de la UNESCO (1993), en Dinamarca, paralelamente, comienzan a surgir este tipo de organizaciones con influjo francés. Por esta razón, en el estudio se consideran estos tres lugares como los pioneros en este ámbito de la educación.

Creemos oportuno distinguir, antes de continuar, los dos tipos de origen a estudiar. Unas serán UPs creadas por Universidades clásicas, y las otras serán UPs fundadas por personas con inquietudes intelectuales y profesionales, pero basándose en el principio de universalidad. En este último lugar en su mayoría obreros, trabajadores e intelectuales; y no hubo otras organizaciones.

Este es el marco en el que desarrollamos nuestro estudio histórico-comparado sobre los orígenes de la Universidad Popular. Sin embargo, conviene establecer los rasgos que consideramos dignos de estudio en dicha aproximación, y explicar teóricamente lo que implica cada caso.

Primero, la Universidad Popular es una institución u organización sociocultural y educativa sin ánimo de lucro (FEUP, 2000), creada por diferentes tipos de agrupaciones, para promover la educación popular dirigida a toda la población. En la educación popular debemos entender todas las modalidades pedagógicas por las que se educa al pueblo (Pineau, 1994). Luego por educación permanente entendemos un orden de ideas, de experiencias y de realizaciones muy específicas, es decir, "la educación en la plenitud de su concepto, en la totalidad de sus aspectos y dimensiones, en la continuidad ininterrumpida de su desarrollo, desde los primeros momentos de la existencia hasta los últimos" (LEGRAND, 1973:57). Y por último, la educación de adultos, se considera un cauce especialmente apto para dar respuesta a los interrogantes y desafíos que plantean las singulares transformaciones producidas en diferentes sectores del saber (Sarrate Capdevilla et al., 2004). Además, constituye un sector específico de la educación social, ya que hace referencia a la etapa más prolongada de la vida, que además, se caracteriza por su gran conexión y proyección social.

\section{PLANTEAMIENTO DE LA HIPÓTESIS Y OBJETIVO DE ESTUDIO}

La hipótesis que queremos plantear es la siguiente, "la introducción de las Universidades Populares dio solución a las carencias educativas y socioculturales de la 
población." Para poder trabajar sobre esta hipótesis vamos a plantear los siguientes objetivos.

- Descubrir la realidad educativa de la época en la que se originan estas instituciones.

- Conocer los fines por los que se crearon estas instituciones.

- Esclarecer las posibles diferencias que puedan existir en cada caso.

- Indagar sobre el motivo de su creación.

- Comprobar si tuvieron influencia ideológica.

\section{METODOLOGÍA}

La metodología que vamos a emplear es la histórico-comparada. Este enfoque nos ayudará a comprobar la hipótesis para demostrar las causas de su origen, la utilidad, ventajas, desventajas de estas instituciones y sus objetivos iniciales.

Practicar el método comparativo consiste en buscar similitudes y diferencias para explicarlas, dentro de una comparación de dos o más realidades. Se trata, además, de ubicar las diferencias, buscar los factores que las ocasionan y fijar las regularidades que se manifiestan entre los procesos observados (BLOCH, 1930).

Coincidimos con Trethewey (1976) en los pasos a usar en cualquier investigación educativa, y que recomiendan diversos autores entre ellos García Garrido (1996).

1. Identificación del problema: presentación de la investigación en la que vamos a trabajar.

2. Formulación de la hipótesis: formularemos una hipótesis que deberá explicar los hechos y los resultados esperados.

3. Definición de conceptos e indicadores: explicación de los conceptos con los que trabajaremos en esta investigación.

4. Selección de los casos: se realizará la selección de los casos que utilizaremos en nuestra investigación y el porqué de su selección.

5. Recolección de datos: haremos un estudio descriptivo de los casos con el que conseguiremos los datos que necesitamos para realizar nuestro análisis comparado.

6. manipulación de datos: para este apartado utilizaremos como herramienta para yuxtaponer los datos, una tabla comparada. Con nuestra tabla podremos recolocar nuestros datos para un posterior análisis descriptivo sobre nuestro estudio.

7. interpretación de los resultados: con los resultados obtenidos realizaremos unas conclusiones que darán significado a nuestra hipótesis.

\section{ORÍGENES}


Una vez aclarado el contexto histórico de la época, nos centraremos en el caso de las UPs en cada país, para poder seguir ahondando en el análisis y establecer la comparación.

\subsection{Origen de las Universidades Populares en Francia}

Francia es considerada como la cuna de fenómenos sociales como organizaciones sindicales, cooperativismo socialista, agrupaciones obreras y la legislación del trabajo. Esto, nos servirá de precedente para dirigirnos hacia los orígenes de las UPs.

Las ideas de los grupos obreros, quedaban plasmadas en La Coopération des Idées, una revista que atraía a los intelectuales de la época y a personas como George Deherme, que está considerado como el fundador de la primera universidad popular. Para él, la democracia debía producirse con la cooperación de todas las voluntades, sin buscar la absorción de las clases, y a través de la educación (TIANA, 1991).

Así, escritores y artistas como É. Zola, A. France, É. Duclaux, F. Buisson, L. Tailhade o G. Séailles, entre muchos otros, se sumaron al esfuerzo pedagógico de Deherme, con tal entusiasmo que La Coopération des Idées se transformó rápidamente en una Sociedad de Universidades Populares que pretendía organizar la enseñanza popular por todo el país (PALACIOS, 1903). Gracias a eso, se recaudaron fondos, que sirvieron para instalar la primera universidad popular organizada como tal, que fue inaugurada en París, en octubre de 1899.

Palacios Morini (1903) señala que, en ese entonces, que no sólo tenían lugar las conferencias magistrales, sino que también se comenzaron a dictar cursos de lenguas extranjeras, fotografía, canto, taquigrafía, dicción y costura. Además, se realizaban consultas médicas, jurídicas y económicas y se brindaba un servicio económico de farmacia. También, tenía lugar el patronato para niños, la organización de colonias de vacaciones, de mutualidades, de cooperativas de todo género, la agencia de colocación y hasta el Teatro social, donde los domingos, además, de contar con una biblioteca con más de 3.000 volúmenes. Gran parte de los intelectuales de la época se fueron maravillando ante tal ejercicio y motor social que esta institución agitaba.

En cuanto a las ideas políticas, casi la totalidad de las UPs de París tendían al socialismo, y además Deherme, fundador de la Universidad Popular parisina, y anarquista. A todo esto, en la época del caso Dreyfus, existía una gran desunión social, a lo que la aparición de la Sociedad de las Universidades Populares da respuesta en 1899. La primera abre sus puertas el 9 de octubre de 1899 en Paris. La Universidad Popular representaba el encuentro de los intelectuales con el pueblo de París (Mercier, 2001). En Francia existían 3 modalidades de UPs: 
- Universidades Populares de La Coopération des Idées: destinado al proletariado, enseñanza superior por la cooperación y concurrencia de todas las ideas, sin exclusión.

- Universidades Populares de "partido": de carácter laico, dirigidas de modo excluyente a grupos de obreros pertenecientes a determinados grupos políticos o asociaciones al servicio de la lucha de clases con miras a conquistar el poder público.

- Institutos Populares: Enseñanza mutua de compenetración y amistad, impulsados por el catolicismo social, no eran de carácter excluyente

Debemos comentar que cuando en Francia no había UPs, las miradas se dirigían a Inglaterra, pues se pretendió reproducir su extensión de la enseñanza. A pesar de todo, en el Reino Unido el real interés por la extensión recaía en ser un método de difusión del espíritu puramente científico (BOWEN, 1992).

Fundamentándose en la obra educativa de la Revolución y en los proyectos de Condorcet, pareciéndose más bien a las colonias universitarias inglesas, incluso por la base cooperativa de sus orígenes. Pensemos en la actuación de Arnold Toynbee en los bajos barrios de Londres, y en su trabajo en esa corriente innovadora en su colonia de Whitechapel (PALACIOS MORINI, 1903). Pero el movimiento francés es íntimamente democrático y popular, en ocasiones hasta plebeyo. En Inglaterra, por el contrario, se asocian a las colonias universitarias con universitarios aristócratas. El movimiento de los instituciones populares que se extienden hasta 1902 y fue muy débil, pues solo se llegó a fundar una en Paris.

Mientras que en las UPs originadas por la extensión universitaria, a las que llamaremos universidades populares extensionistas, tiene un programa repleto de cursos, trabajos de alumnos y hasta diplomas. En las UPs casi no se pudo pasar de las conferencias aisladas. Pero ésta, cuenta con la más rica variedad en programas, métodos, ideas, conferenciantes y asuntos más mezclados. La reglamentación uniforme es buena para los profesionales, pero, para los obreros que no podrían seguir un plan riguroso, dadas sus condiciones de vida y de trabajo, no lo era. Y algo que, para el obrero, significa el esfuerzo de orientación para formarse su propio programa, según sus inquietudes.

\subsection{Origen de las Universidades Populares en Dinamarca}

En la Dinamarca del siglo XIX existieron varios movimientos liberales y nacionalistas, mezclados con conflictos territoriales con los países vecinos. La monarquía, se convirtió en constitucional. En ella, el poder ejecutivo recaería sobre el rey. El poder legislativo se repartiría entre dos cámaras parlamentarias, una para la vieja aristocracia y a la otra asistiría la clase media (LAURING, 1995). 
El concepto original del término de Universidad Popular se atribuye al importante maestro, escritor, filósofo y pastor luterano danés Grundtvig (1783-1872), que se inspiró en el Informe para la Organización General de la Instrucción Pública, del filósofo Concordet, escrito en el año 1792, durante la Revolución Francesa. Condorcet habla sobre sus principios para conseguir una política educativa con rigor científico, pero con bases laicas, democratización de la enseñanza, con el fin de formar ciudadanos autónomos, instrucción para todas las edades, libertad de cátedra, igualdad de acceso a la educación para hombres y mujeres, y el anti-utilitarismo entre otras características. Además de la autonomía de la enseñanza frente al poder ejecutivo o promoción del talento individual (UNESCO, 1993).

La principal inquietud de Condorcet fue de carácter humanista, dirigido hacia la instrucción pública, que tiene por tarea ayudar a todo ciudadano a deliberar consigo mismo y con los otros. En cambio, para Grundtvig, sus inquietudes adquirían otras prioridades en referencia a la educación popular, viéndose marcada por el contexto basado en un conflicto territorial germano-danés.

Grundtvig a lo largo de su vida contó, de forma casi constante, con la protección real. En 1818, mucho antes de ser nombrado capellán en Vartov y de que Federico VII le concediera el título de obispo honorario, recibió un subsidio real, en señal de recompensa por haber traducido mitos y sagas del noruego antiguo con fines nacionalistas. En favor de estos subsidios reales, Grundtvig pudo visitar en varias ocasiones Inglaterra, con fines de estudio de la mitología nórdica, así mismo, tuvo ocasión de observar de cerca la educación inglesa.

Con los cambios radicales acaecidos en la escena política y social de Dinamarca hicieron que Grundtvig produjera en la década de 1830 una serie de escritos, en los que aparece por primera vez la idea de la Universidad popular de adultos. (JENSEN, 1987:50). Es más, en el prefacio a su estudio sobre la mitología escandinava publicado en 1832 con el título Mitología Nórdica se vislumbran los primeros indicios de las futuras escuelas populares danesas. Aunque, en tal obra, las ideas de Grundtvig sobre una institución de enseñanza popular aparecen aún en un estado rudimentario, esta obra constituye un ensayo general de lo que, más tarde, iban a ser los ataques de Grundtvig contra las escuelas para la muerte o escuelas negras, como llamaba a los centros de enseñanza tradicional, como explicaremos más adelante.

Cabe destacar que Grundtvig se llamaba irónicamente a sí mismo escaldo, poetaguerrero de origen vikingo. Él pensaba que estos escaldos, bardos o juglares eran los verdaderos maestros del pueblo pues despertaban y alimentaban con amor a la patria, además de enriquecer la lengua materna. En relación a esto, no nos sorprende la importancia de los mitos, leyendas o poemas en danés que se recomendaban en el programa de estudios de las primeras UPs (UNESCO, 2000). 
Posteriormente parece que las escuelas fueron excesivamente nacionalistas, pero ello se debe solamente a las circunstancias históricas del momento, ya que existía un conflicto entre la corona danesa y la confederación austro-prusiana por la parte sur danesa, los ducados de Schleswig y Holstein. El autor apoyaba fervientemente el uso de la lengua y la oratoria como instrumento educativo y cultural de transmisión. Ejemplo de ello, es que Grundtvig en su campaña por la tradición oral, atacaba a la escuela tradicional tachándola de escuelas para la muerte en contra de sus escuelas populares nombrándolas escuelas para la vida (JENSEN, 1987: 50). En estas afirmaciones podemos ver una similitud con el pensamiento educativo de Paulo Freire, en el cual, tacha a las escuelas tradicionales de impartir una enseñanza que sólo está basada en llenar cabezas de los conocimientos que a la opresión le interesa enseñar, y ocupar las mentes de tal forma que no les permita al pueblo oprimido desarrollar una conciencia crítica, para evitar transformación alguna y seguir oprimiendo (FREIRE, 1977).

A su vez, Grundtvig se vuelca en la organización de la institución de educación popular, preocupándose por aspectos como el consejo de estudiantes, la enseñanza mutua o los debates sobre cuestiones que preocupaban a la comunidad danesa. Este último con miras a que si el pueblo interviniera en un futuro próximo en el destino de la nación danesa por medio de los consejos del pueblo, sería provechoso que dicho pueblo tuviera una formación en materia de autogobierno en las UPs.

Grundtvig le da al director el título de organizador, concepción que viene recibida gracias a la ideología de enseñanza mutua que el autor sostiene (UNESCO, 1993). Las UPs deberían de estar formadas además por estudiantes de diferentes estratos socioeconómicos y diferentes grupos de edad, así, con ello, reforzar el espíritu de compañerismo y contribuir a que prevalezca la condición común de los seres humanos sobre las creencias políticas y religiosas.

Sorprendentemente, siendo Grundtvig un personaje clérigo pensaba que la iglesia no era un círculo de lectura de la biblia simplemente, sino una comunidad de creyentes. Esto nos lleva a entender que la enseñanza religiosa no entraba en los planes de Grundtvig para la Universidad popular, pues era tema de impartición que correspondía a la iglesia únicamente. Este deseo de suprimir la formación religiosa de sus escuelas se resume en este principio: "El primer lugar, el ser humano; después el cristiano" (LAWSON, 1993:655)

Así, entendemos que antes de ser cristiano, se ha de ser un ser humano auténtico. Resumiendo, los pensamientos pedagógicos de Grundtvig se centran en conseguir una fraternidad entre educador y educando; la importancia de la palabra viva, la insistencia en la condición humana y la cuestión en educación de reciprocidad viva, que conlleva la ilustración y comprensión de la propia existencia, huyendo de la formación profesional y la instrucción formal. 


\subsection{Origen de las Universidades Populares en Reino Unido}

No sería correcto decir que fue en territorio británico donde aparecieron las primeras Universidades Populares, pero sí en donde surgieron las primeras instituciones que servirían de génesis para la fundación de estas. En relación con su origen hablaremos sobre los University Settlements (las colonias de extensión universitaria inglesa) y las escuelas lancasterianas, promovidas por la reforma de la educación pública y la metodología de la enseñanza mutua.

Los principales promotores de lo que terminó por nombrarse Universidad Popular mediante extensión universitaria, fueron las Universidad de Cambridge y Oxford. Dichas instituciones tenían aspiraciones para enriquecer culturalmente al sector marginado. Esa era la manera de reunir a las dos partes del sector en una misma institución con tal fin. Estas instituciones, pertenecientes a las colonias universitarias, tomaron la iniciativa de que sus alumnos tuvieran contacto con la realidad de la situación. En ella, se encontraron con un gran índice de analfabetismo e incultura.

En este sentido, es importante mencionar las diferencias existentes desde el punto de vista conceptual entre las características y definiciones que adquirió la extensión universitaria con las llamadas universidades populares: la extensión era una expresión de la lógica e ideario de la universidad; mientras que las universidades populares eran instituciones, en general, desvinculadas de las universidades tradicionales (salvo algunos casos particulares) y donde se practicaba la enseñanza de forma limitada y con cierto tono de vulgarización (MENÉNDEZ, 1996).

Las conferencias de vulgarización, para un público más numeroso, y más populares, tenían lugar los sábados. Casi todas las celebridades de Londres han pasado por la gran sala de la Colonia, y hablado de los asuntos más variados a los habitantes del barrio. Pero las reuniones más celebradas, eran los jueves, y eran denominadas Smoking debates (CLAPARÈDE, 1898).

La situación educativa en Inglaterra que tenía como epicentro las Grammar Schools que se encontraban en un lamentable estado y con problemas de disciplina. En estas escuelas, se alcanzaba un dominio suficiente de las lenguas clásicas (latín y griego clásico) que posibilitaban la entrada a alguna de las pertenecientes al conjunto de universidades inglesas (Cambridge y Oxford), como señala Tiana (2002): "si un joven, después de pasar 4 ó 5 años, la deja a los 19, incapaz de construir un trozo en latín o griego sin ayuda del diccionario o describir latín con corrección gramatical" (p. 123), casi ignorante de la geografía o de la historia de su propio país, desconocedor de cualquier lengua moderna que no sea la suya, y escasamente competente para escribir correctamente en inglés o hacer una pequeña cuenta matemática. Totalmente ajenos estos chicos de las leyes que gobiernan en 
el mundo físico y a su estructura, con ojo y una mano hábiles para el dibujo y sin conocer una nota de música, con una mente no cultivada y ningún gusto por la lectura o la observación, su educación intelectual debe considerarse ciertamente un fracaso, aunque no haya nada que objetar a sus principios, carácter o modales ${ }^{l}$.

Ahora bien, ¿qué diferencia había entre la extensión universitaria británica y la universidad popular francesa? La extensión universitaria, que tuvo su origen en Gran Bretaña pero que se multiplicó rápidamente, por Viena, Turín y Oviedo, y propició la fundación de universidades populares que estaban adscritas a la figura y los recursos de una Universidad tradicional: realizaban sus actividades en las instalaciones de ésta, y disponían asimismo de sus profesores y sus métodos.

\subsubsection{Toynbee-Hall: una de las consecuencias de la extensión universitaria británica}

Toynbee-Hall es una de las instituciones perteneciente a los University Settlements; siendo así la colonia universitaria de Whitechapel, Londres. Entre ésta, figuran con muchas más, como Glásgow, Bristol, Mánchester y Edimburgo (Palacios Morini, 1903). La labor popular de Inglaterra pasaría por los cursos nocturnos, de la Extensión universitaria, de las instituciones politécnicas, de las de educación social del obrero, de las sociedades de lectura, de bibliotecas y enseñanza para la mujer.

El centro de Toynbee-Hall era dirigido por un clérigo, cuyos objetivos eran: disminuir la desconfianza entre ricos y pobres, favorecer el acercamiento de unos a otros, llevar a la administración local un espíritu noble y de conciencia sobre la misión del ciudadano. Existe, por otra parte, una dualidad en la enseñanza, diurna y nocturna. Se dividía las clases en cursos regulares de Extensión universitaria por el día, y por la tarde se realizaban conferencias de divulgación para el gran público. Un Settlement es simplemente un club en un barrio industrial; club en que la sola condición es llenar el deber del ciudadano; una habitación entre los pobres, donde prosperen corrientes de amistad igual y recíproca, no de mera tutela y subordinación humilde (BUISSON, 1896).

Esto estaría así pensado para que los alumnos tomasen contacto con la fuente del conocimiento y de esta manera no tuvieran información de segunda mano para que puedan formar ideas propias. La participación de las universidades de Oxford y Cambridge contribuyó a que perdieran por momentos su carácter aristocrático y sectario. Llevaban fuera de sus muros los beneficios de su acción, buscando al pueblo, a donde no llegaban, y así nacía la Extensión universitaria.

"Pero los cursos de conferencias de la University extension no bastaron; había quien no sentía la necesidad de instruirse, había quien no sufría la influencia de la instrucción en la conducta. El

${ }^{1}$ El Informe Clarendon refleja esta situación educativa del país. 
profesor de Oxford Th. Hill Green, hizo comprender que no se trataba de repartir limosnas y sí de dar a los pobres, con nuestra vida intelectual, una parte moral afectiva, y también cuajaron estas enseñanzas" (PALACIOS, 1903:162).

Al igual que ocurría con las escuelas secundarias, las universidades inglesas se habían quedado atrasadas desde el punto de vista académico. Sus enseñanzas también eran de tipo clásico, excluyendo prácticamente a las disciplinas científicas de sus planes de estudio. Además, estaban monopolizadas por la Iglesia anglicana, con los consiguientes intereses ideológicos y políticos que conlleva (TIANA, 2002).

Como dato a destacar, se tenía costumbre de celebrar unos debates denominados Smoking debates un día a la semana, en el cual, varios obreros colmaban un gran salón donde se reunían ociosamente para fumar y debatir sobre asuntos de la actualidad, además de invitar a alguna persona autorizada a presentar, brevemente, el asunto de debate. Tienen las enseñanzas de Toynbee-Hall, las que según Claparède (1898), poseen un doble carácter: cursos regulares de la Extensión universitaria, y conferencias de vulgarización para el gran público que se hacían de noche.

Para promover el interés y la actividad por estos asuntos, se forman clubs y asociaciones que siguen un curso de estudios sobre un objeto particular. Por ejemplo la asociación Shakesperiana, la Isabelina, y algunas otras literarias, confederadas en una Sociedad general, en la que también se reunían el club de economistas, o el de filósofos y algún otro, en los que se leen y discuten memorias en armonía con su objeto. También, existía un laboratorio químico donde se practicaban operaciones básicas, una Biblioteca con más de 7.000 volúmenes dados o prestados por escritores o editores. Entre las actividades realizadas en el Toynbee-Hall se daban clases de noche, donde se enseñaba a leer y a escribir o cursos de economía. Asimismo, existían asociaciones de estudiantes y antiguos estudiantes independientes a la institución. Dichas agrupaciones estaban formadas para realizar actividades fuera de la institución, tales como realizar excursiones, visitas o garden parties en propiedades de amigos, con fines de fomentar una unión entre estudiantes (PALACIOS, 1903).

Tabla 1. Tabla comparativa entre los orígenes de las Universidades Populares en Dinamarca, España, Francia y Reino Unido.

\begin{tabular}{|l|l|l|l|}
\hline & $\begin{array}{l}\text { Universidad Popular } \\
\text { en Dinamarca }\end{array}$ & $\begin{array}{l}\text { Universidad Popular } \\
\text { en Francia }\end{array}$ & $\begin{array}{l}\text { Universidad Popular } \\
\text { en Reino Unido }\end{array}$ \\
\hline $\begin{array}{l}\text { Aparecen a partir de } \\
\text { la extensión } \\
\text { universitaria }\end{array}$ & & $\mathrm{X}$ \\
\hline $\begin{array}{l}\text { Aparecen a partir de } \\
\text { diferentes iniciativas } \\
\text { del pueblo o del }\end{array}$ & $\mathrm{X}$ & $\mathrm{X}$ & \\
\hline
\end{tabular}




\begin{tabular}{|c|c|c|c|}
\hline Estado & & & \\
\hline $\begin{array}{l}\text { Con finalidad de } \\
\text { profesionalización }\end{array}$ & & $X$ & $\mathrm{X}$ \\
\hline $\begin{array}{l}\text { Con finalidad } \\
\text { alfabetizadora }\end{array}$ & $\mathrm{X}$ & $X$ & $\mathrm{X}$ \\
\hline $\begin{array}{ll}\text { Impulsadas } & \text { por } \\
\text { intelectuales } & \end{array}$ & $\mathrm{X}$ & $X$ & $\mathrm{X}$ \\
\hline $\begin{array}{lr}\text { Financiadas } & \text { por el } \\
\text { Estado u } \quad \text { otras } \\
\text { instituciones }\end{array}$ & $\mathrm{X}$ & & $\mathrm{X}$ \\
\hline $\begin{array}{l}\text { Financiadas } \quad \text { por } \\
\text { implicados }\end{array}$ & $\mathrm{X}$ & $X$ & \\
\hline $\begin{array}{ll}\text { De } & \text { carácter } \\
\text { voluntario } & \end{array}$ & $\mathrm{X}$ & $\mathrm{X}$ & $\mathrm{X}$ \\
\hline De carácter rural & $\mathrm{X}$ & & \\
\hline De carácter urbano & & $X$ & $\mathrm{X}$ \\
\hline $\begin{array}{l}\text { Recepción de todos } \\
\text { los estratos sociales }\end{array}$ & $\mathrm{X}$ & $X$ & $\mathrm{X}$ \\
\hline Ideología socialista & $\mathrm{X}$ & $\mathrm{X}$ & $\mathrm{X}$ \\
\hline Influencia sindical & & $\mathrm{X}$ & $\mathrm{X}$ \\
\hline $\begin{array}{l}\text { Centralizada } \\
\text { (Presencia en la } \\
\text { capital del país } \\
\text { desde el principio) }\end{array}$ & & $\mathrm{X}$ & $\mathrm{X}$ \\
\hline $\begin{array}{l}\text { Con apoyo del } \\
\text { Estado }\end{array}$ & $\mathrm{X}$ & & \\
\hline De carácter laico & $\mathrm{X}$ & $X$ & $\mathrm{X}$ \\
\hline De carácter ocioso & $\mathrm{X}$ & $\mathrm{X}$ & $\mathrm{X}$ \\
\hline Pioneras & $\mathrm{X}$ & $\mathrm{X}$ & $\mathrm{X}$ \\
\hline
\end{tabular}

Fuente: elaboración propia.

\section{ANÁLISIS DE LOS RESULTADOS}

El movimiento siempre estará orientado a la educación social con ejercicio de la alfabetización del ciudadano. Estos movimientos, por consiguiente, buscan un cambio social en el pueblo, para conseguir ciudadanos con pensamiento más crítico y las habilidades básicas pertinentes.

Hemos podido ver que siempre han sido de carácter voluntario, y nunca obligatorias, pues estas instituciones estarían englobadas dentro de educación para toda la vida o la educación permanente. Así, debemos entender que la mayoría de los asistentes irían motivados por interés personal intelectual y cultural. 
Luego en todos los orígenes coinciden en mayor o menor medida la ociosidad de tales Universidades Populares puesto que en todas comparten el interés por utilizar la oralidad o palabra hablada como transmisión de conocimientos y saberes. En todas se reiteran las actividades al aire libre, excursiones, visitas culturales o naturales. Visto ello, queda por ver que, incluso con normalidad, existían en estas instituciones agrupaciones de antiguos alumnos que celebraban estas actividades ociosas. De esta manera la permanencia a las instituciones se alarga, y por tanto, en menor o mayor medida su objetivo educador.

Siempre habrían de ser instituciones no influidas por ideologías, cultos o religiones. Recordando el principio de universalidad, coincidiremos en la utilización de la institución como herramienta de unión de la comunidad dentro de un mismo movimiento de transformación social. Podemos ver, que ni en el caso de Dinamarca, teniendo un pensador religioso, se siguió respetando el principio de universalidad, pensándose así, por el bien de la sociedad.

Centrándonos más en cada origen estudiado, podemos ver que las génesis danesa y francesa están claramente influidas por las ideas revolucionarias de Condorcet. En el caso danés, por la inspiración de Grundtvig en el informe del teórico francés y en el sentimiento de necesidad de su nación ante los acontecimientos políticos a los que se enfrentaban la aparición de la monarquía constitucional, y por consiguiente con las cámaras parlamentarias en las que participaría el pueblo.

En el caso francés, las agrupaciones sindicalistas coinciden también con el pensamiento de Condorcet de conseguir la igualdad de derechos o de la capacidad de cualquier ciudadano de desempeñar las actividades de cualquier oficio. Pero además, estas instituciones tendrían un tinte anarquista promovido por el sindicalista George Deherme.

Por otro lado, la génesis británica estaría influida por el método de enseñanza mutua de Bell y Lancaster, fomentado por las consecuencias de la revolución industrial en la sociedad. Esto terminaría deviniendo en los primeros coloquios de estas instituciones. Así, también deberíamos darle mención a la aparición de los movimientos sindicales británicos como influencia en las Universidades Populares, al igual que pasó en Francia.

Las Universidades Populares británicas serían promovidas por las Universidades de Cambridge y Oxford, a modo de extensión a través de las colonias universitarias. En estas instituciones se promovían actividades que acercase la realidad de la situación educativa nacional a sus estudiantes, ante el problema reinante en sus "Grammar Schools" (TIANA, 2002).

La finalidad de estas instituciones es variada según el lugar donde se originan. En el caso danés se caracteriza por unos fines más beneficiosos para la nación, pues la búsqueda 
principal de estas instituciones fue la alfabetización y mejora del pensamiento crítico del pueblo danés. La finalidad última sería la de una buena participación del pueblo en las asambleas locales. En pocas palabras, el interés se adentra en el cambio social como motor de avance nacional, y, en definitiva, en la educación al ciudadano o para la ciudadanía.

En otros casos, la aparición de estas instituciones tiene intereses con tintes capitalistas. Por ejemplo, el modelo británico, principalmente llevado a buen puerto por la extensión de las grandes universidades. En principio tuvo un fin social con el cual realizar un acercamiento entre diferentes estratos sociales de la época en alegres charlas nocturnas. Pero también existe un interés indirecto de las fábricas a conseguir mejorar la mano de obra en sus industrias, ya que mejorar la calidad del trabajo es un ideal consumista derivado de consecuencias de la revolución industrial.

Luego, el apoyo a estas instituciones sería variado. Existen casos, como el británico, que está apoyado por instituciones de mayor liderazgo como las Universidades de Cambridge y Oxford. O bien por diversos personajes e intelectuales interesados en la mejora cultural del pueblo como por ejemplo el conde de Chambrun en Francia y su museo social (Palacios Morini, 1903). Y más tarde, por otro lado, está el caso danés, en la cual tales instituciones serían apoyadas por la monarquía con el interés de fomentar el nacionalismo, por culpa de sus conflictos territoriales con Alemania.

También debemos comentar que las actividades no se daban como clases magistrales, como conocemos en otras instituciones educativas, sino de una manera mucho más dinámica, siendo así conferencias de vulgarización o coloquios, cursos de corta duración o excursiones entre otras. Así tenían un carácter ocioso y dinamizador. En ningún momento se buscaba realizar actividades pesadas o monótonas para trabajadores y obreros, que hacían el esfuerzo y tenían la incertidumbre de asistir a estas instituciones después de una larga jornada laboral.

También hay disparidad en la preferencia entre medio rural y urbano, pues depende del lugar de origen estudiado, estas instituciones aparecen con objetivos más marcados, pues en Francia y Reino Unido con intención de profesionalizar más al obrero, y en Dinamarca existían con el interés de fomento de aptitud crítica más marcada.

Coincide también que en la mayoría de las primeras Universidades Populares aparecieron en las capitales de sus países, exceptuando a Dinamarca que tenía su objetivo marcado en dirección a zonas rurales.

Al estar centralizadas, podríamos calificar estas instituciones como un movimiento social pionero de nuevo orden, con epicentro en las capitales de expansión a zonas rurales. 
Es decir, desarrollo del movimiento con principio en la capital del país, y continuación en regiones más apartadas.

En todos los orígenes estudiados, se puede comprobar que recibían a cualquier persona interesada en aprender sin importar su procedencia, principio de universalidad. Tomando como ejemplo el Reino Unido, que tomó como objetivo de importancia, la reunión de personas de diferentes estratos sociales y nivel adquisitivo en una misma sala.

También en referencia a la ideología política, podemos ver que en general son instituciones con ideas progresistas, pero el conservadurismo también se impone con intereses industriales y mejora de la mano de obra. En Reino Unido se impone la importancia del consumismo, con miras a evolución del sistema de trabajo y perfeccionamiento de la producción. En Francia con gran ideología socialista marcada, la Universidad Popular se centra más en las necesidades del obrero y trabajador. En Dinamarca con su objetivo social, sería el bien del Estado, por medio de educar a sus conciudadanos, para poder ser más críticos con la política del gobierno.

Por último, debemos advertir el carácter laico que existen en estas instituciones, pues en todo momento se respeta el principio de universalidad. El más claro ejemplo, está en la génesis danesa, donde su ideólogo, siendo clérigo, respetó en su obra la idea de universalidad en estas instituciones, pero aun así con el matiz de ser una nueva institución al servicio del Estado, en las circunstancias históricas de la Dinamarca del momento. En cuanto al resto de instituciones, en las demás génesis, se desarrollaron de la misma manera, respetando el principio de universalidad.

\section{CONCLUSIÓN}

Después del análisis histórico comparado sobre el origen de las universidades populares en estos tres países europeos podemos contestar a los objetivos de investigación del trabajo, que las Universidades Populares son instituciones educativas y culturales creadas por grupos, asociaciones y organizaciones sociales para promover la educación popular de saberes teóricos y prácticos, dirigida a toda la población, en especial a sectores populares como trabajadores, campesinos, emigrantes o mujeres que no tienen acceso a la educación. En sus inicios se ideó como educación sin ánimo de lucro, con fines ociosos de los trabajadores u obreros que tenían inquietudes intelectuales, que sofocaban asistiendo a estas tertulias, conferencias o pequeños cursos. Entendiendo el fin ocioso como aquello no ligado al trabajo.

Por lo tanto, en estas instituciones se daba esta educación popular, basada en el desarrollo del sentido crítico y dialéctico. Se usaban recursos fundamentalmente orales e 
intelectuales. En el caso británico, lo vemos en los smoking debates, muy del gusto de Claparède en la colonia universitaria de Toynbee-Hall.

Se considera como una educación propia y protagonizada por los propios sujetos que buscan el cambio. Principalmente dirigida hacia los adultos y trabajadores que quieren seguir formándose y aprender, es más democrático y cooperativo que los métodos tradicionales de educación de los salones de clase, basados en lecturas y escrituras por expertos. Debemos entender el concepto de adulto como el movimiento en que una persona trabajaba y no como hoy que es a partir de la mayoría de edad establecida por cada país.

También debemos observar que se busca conseguir el principio de universalidad en estas instituciones. Serían centros educativos donde la ideología no tenía cabida y, donde las personas en los procesos de educación popular más comunes y corrientes, definen sus propios problemas y aplican las lecciones de los éxitos y los fracasos en situaciones reales. Los sujetos aprenden a reflexionar e interpretar críticamente su forma de vida. Esto crea a nuevas personas con la capacidad crítica suficiente para no ser influidas por ideologías o religiones, otro discurso es que personas con diferentes ideologías aprovechen los servicios de estas instituciones. En conclusión, es una educación que equilibra los poderes hegemónicos tradicionales del Estado, la Iglesia o el mercado.

Centrándonos en nuestro estudio debemos advertir que en todos y cada uno de los casos se han seguido los ideales de la educación popular, exhibida en mayor o menor grado, pero poniendo más énfasis sobre la inquietud del sujeto por saber más y contener una motivación intelectual de querer saber más.

Por los datos que hemos recopilado en nuestra tabla comparativa podemos sacar varias ideas. Una de ellas es que la educación popular se originó antes en lugares donde se propiciaban cambios importantes, ya sean a raíz de la revolución industrial y su suceder de acontecimientos o por conflictos territoriales y gubernamentales como en Jutlandia (Dinamarca). Siendo así, las grandes potencias pioneras como Francia y Reino Unido, países en los que aparecen estas instituciones desde el comienzo en sus capitales. Por ello entendemos que los movimientos históricos de una manera o de otra incitaron a la aparición de estas instituciones para satisfacer la necesidad formativa compaginándola con las actividades lúdicas y de ocio. Esto también apoya a la formación a lo largo de la vida que con el devenir del tiempo se ha convertido en casi un deber para el buen funcionamiento de las funciones que pueda desempeñar cualquier empleado.

Es una conclusión clara, que se originan por inquietudes intelectuales y laborales, en muchos casos profesionalizando al sujeto como por ejemplo en los casos de las Universidades Populares en Asturias donde se abrieron estas instituciones para dar respuesta a las necesidades de obreros de minas y astilleros (PALACIOS, 1903). En otros 
casos con intereses socializadores, como en Reino Unido, aunando diferentes estratos sociales de fortuna y pobreza en una misma institución para el enriquecimiento educacional conjunto, comprobando que existen diferentes Universidades Populares con diferentes características.

Llegaban a todos los puntos geográficos donde hiciera falta educación permanente, ya sea en zonas más rurales, las capitales del país o bajo el manto de grandes Universidades. Por ejemplo, en Reino Unido o en Francia, aparecerán más instituciones de este tipo en las urbes que en zonas rurales, ya que los interesados eran trabajadores de las fábricas. Además, también coinciden que las primeras Universidades Populares de sus países aparecen en sus capitales con idéntico interés narrado, exceptuando Dinamarca que fue el único origen estudiado que fue apoyado directamente por el estado, ya que se necesitaba una buena alfabetización para el pueblo danés por los cambios gubernamentales que se vivían en el momento.

Estas instituciones se nutrirán principalmente de estudiantes de la clase obrera, aunque las puertas están abiertas a cualquier persona de diferente estrato. Pero, naturalmente, buscando la ociosidad. No sería muy motivador que un sujeto después de una jornada completa de trabajo entrara dentro de un ambiente serio y poco dinámico, por ello las charlas y conferencias o actividades al aire libre.

Desde el punto de vista político, podemos ver claramente un ideal progresista en la creación de estas instituciones, pero también podemos ver que la ideología conservadora se vale de estas instituciones para conseguir en algunos casos, obreros mejor preparados para sus fábricas.

Otro punto a destacar es la autogestión por la que pasaban estas instituciones al no estás sistematizadas por el estado, ni influidas por la iglesia, ya que son de carácter laico. El teórico Grundtvig dejó claro que su ideal de Universidad Popular no pasaba por la influencia religiosa pues en primer lugar, le interesaba el ser humano; después el cristiano (LAWSON, 1991).

Apreciamos diferencias aparecidas entre las distintas génesis. Ya que pueden darse como semilla de una Universidad u originada directamente por medio de agrupaciones que tengan inquietudes intelectuales y culturales.

En resumen, las Universidades Populares fueron desde sus principios iniciativas no excluyentes, que iban dirigidas a un público con pluralidad ideológica. La aparición de estas instituciones se basó en ideales utópicos, como un requerimiento de la democracia, regeneración social por lo tanto esto era: 
"una hermosa aspiración científica, un anhelo educativo, un admirable deseo de mejorar, de elevarse por medio de la cultura, la cual no consiste sólo en saber unas cuantas cosas, sino en formarse de cierta manera" (POSADA, 1903:233-234).

Dicho esto, entendemos la educación popular como vía de transformación de la sociedad. La introducción de las Universidades Populares daría entonces solución a las carencias educativas y socioculturales de la población. En muchos casos los alfabetizó, en otros, indirectamente se supone que optimizó el ejercicio diario de su trabajo, sin haber coincidencia con el oficio que tuviese. Ayudó sobremanera a aumentar y fomentar los conocimientos de los trabajadores, además de ampliarlos y saciar sus inquietudes de aprendizaje.

\section{REFERENCIAS BIBLIOGRÁFICAS}

ANGUlO, E. \& BENAVENTE, J. et Al. (1990): Educación de Adultos y Democracia. (Madrid: Editorial Popular \& O.E.I).

BADILLA SAXE, E. (2012): La Universidad de Costa Rica en tránsito. Revista de actualidades investigativas en Educación, 12 (1), pp. 1-37.

BARREIRO, J. (1979): Educación popular y proceso de concientización. (México: Editorial Siglo XXI).

BENSO CALVO, C. (1999): La Universidad Popular de Ourense, Anuario Galego de Historia da Educación, 3, pp. 257-263.

BLOCH, M. (1930): Comparación. Revue de Synthèse Historique, Tomo. LXIX, pp. 15-50.

BOWEN, J. (1992): Historia de la educación occidental: el Occidente moderno, Europa y el nuevo mundo: siglos XVII-XX. (Barcelona: Herder).

BUENO MARTÍNEZ, G. (2002): Fundación social de la Universidad Popular. El Catoblepas, 5, pp. 2-11. Extraído de http://www.nodulo.org/ec/2002/n005p02.htm

BUISSON, F. (1896): L'Éducation populaire des adultes en Anglaterre. (Paris: Hachette).

CABALlOS BEJANO, M. G. (2002): El "affaire Dreyfus": un caso de xenofobia y antisemitismo del S.XX. Philologia hispalensis, 16, pp. 37-71.

CAPELLÁM REY, A. (1999): Contribucións a unha historia da Universidad Popular da

Coruña, Sarmiento. Anuario Galego de Historia da Educación, 3, pp. 25-64.

CANTERO, C. (2006): El concepto de la extensión universitaria a lo largo de la historia, Universidades Públicas Andaluzas. Extraído de http://observatorioatalaya.es/uploads/pdf/7b4531ef25de381a3d296d64efc3bf6be070 eefd.pdf

CLAPARÈDE, R. (1898): Toynbee-Hall: une colonie universitaire en Anglaterre, Paris: Librairie de la société du recueil général des lois et des arrêts et du journal du palais.

CORTS GINER, M. I.; ÁVILA FERNÁNDEZ, A.; CALDERÓN ESPAÑA, M. C. \& MONTERO PEDRERA, A. M. (2004): Historia de la educación, fundamentos y práctica investigadora. Sevilla: Edición Digital @ tres. 
DA COSTA, R. (2006): Las definiciones de las siete artes liberales y mecánica en la obra de Ramón Llull. Anales del Seminario de Historia de la Filosofía, 23, pp. 132-140.

DELGADO GRANADOS, P. (2010): Educación, democracia y ciudadanía en el siglo XXI desde el proyecto político educativo de Paulo Freire. Revista Fuentes, 10, pp. 140153.

FEUP (2000): Aprendiendo en la sociedad del conocimiento. Albacete. Extraído de http://www.dipualba.es/publicaciones/Varias/Otras/TeorUUPP.pdf

FREIRE, P. (1977): La educación como práctica de la libertad. México: Editorial Siglo XXI.

GALLARDO VÁZQUEZ, P. \& RUIZ CURADO S. (2007): Educación permanente, educación popular y asociacionismo. Sevilla: Departamento de Teoría e Historia de la Educación y Pedagogía Social de la Universidad de Sevilla.

GALLARDO VÁZQUEZ, P. \& RUIZ CURADO S. (2008): Reflexiones sobre educación popular, instituciones y ámbitos territoriales. Sevilla: Wanceulen educación.

GARCÍA GARRIDO, J. L. (1996). Fundamentos de la Educación Comparada. (Madrid: Dykinson).

GARCÍA MORILLA, A. \& GONZÁLEZ RUEDA, A. (1999): La Extensión Universitaria. Cien años de formación integral para el universitario. En Jornadas de Gestión Cultural. Alicante. (pp. 15-19).

GUEREÑA, J. L. \& TIANA FERRER, A. (1994): La educación popular, pp. 150-154. En GUEREÑA, J.L.; RUIZ BERRIO, J. y TIANA FERRER, A. (eds.): Historia de la Educación en la España Contemporánea. Diez años de investigación. (Madrid: Centro de Publicaciones del Ministerio de Educación y Ciencia).

GVIRTZ, S.; GRINBERG, S. \& ABREGÚ, V. (2007): La educación ayer, hoy y mañana. El ABC de la pedagogía. Buenos Aires: AIQUE.

HALEVY, D. (1901): Essais sur le mouvement ouvrier en France. (Paris: Sociéte nouvelle de libraire et d'édition).

HOPMANN, S. (1991): El movimiento de Enseñanza Mutua y el desarrollo de la administración curricular: Enfoque comparado. Revista de Educación, 295, pp. 291396.

JÁUREGUI, R. M. (2003): El método de Lancaster. Educere, El aula, vivencias y reflexiones, 7 (22) pp. 225-228.

JENSEN, N. L. (1987): Grundtvig Anthology: selections from the writting of N. F. S. Grundtvig, (USA: Lutterworth Press).

LAURING, P. (1995): A history of Denmark. (Copenhagen: Host).

LAWSON, M. (1991): NFS Grundtvig: selected educational writings. (Denmark: HandyPrint).

LEGRAND, P. (1973): Introducción a la educación permanente. (Barcelona: Teide/ UNESCO). 
LÓPEZ NÚÑEZ, J. A. \& LORENZO MARTÍN, M. E. (2009): Universidades Populares en España y su relación con la universidad suramericana. Revista Educación y Educadores, 12 (1), pp. 156-167.

MEDINA CARBALLO, M. (1999): Las escuelas lancasterianas en México. México: Universidad Pedagógica Nacional.

MENÉNDEZ, G. (1996): Desarrollo y conceptualización de la extensión universitaria. Universidad Nacional del Litoral, pp. 8-12.

MERCIER, L. (2001): La educación popular a través de la Universidad Popular en la Francia del primer siglo XX. Historia de la Educación: Revista interuniversitaria, 20, pp. 117-135.

MORENO MARTÍNEZ, P. L. \& SEBASTIÁN VICENTE, A. (2010): Las Universidades Populares en España (1903-2010). CEE Participación Educativa, número extraordinario, pp. 165-179.

MORENO MARTÍNEZ, P. L. (2005): Haciendo memoria: las Universidades Populares en España. (Tabanque: Revista pedagógica), 19, pp. 21-40.

NEILA MUÑOZ, C (1999): "La Educación de Adultos en España en el Siglo XX, Una perspectiva histórica". Extraído de http://www.amautainternational.com/EduAduXX.htm

PALACIOS MORINI, L. (1903): Las Universidades Populares. Madrid: La España Moderna. Extraído de http://www.filosofia.org/aut/lpm/index.htm

PINEAU, P. (1994). El concepto de 'educación popular' un rastreo histórico comparativo en la Argentina. Revista de educación, 305, pp. 257-278.

POSADA HERRERA, A. (1903): Las universidades populares. La revista socialista, 8, pp.231-236.

PUENTE, J.M.; FERNÁNDEZ, A. \& CÍA (1986): Perspectivas para la educación de adultos. (Barcelona: Editorial Humanitas).

RAZETO, L. (1990). Educación y desarrollo local. En OSORIO, J., Educación de adultos y democracia. (Madrid: Popular), pp.105-119.

RÍOS GONZÁLEZ, M.F. (2007): Perspectiva histórica del concepto de educación permanente. (Sevilla: UNED).

RODRÍGUEZ-SAN PEDRO BEZARES, L. E. \& POLO RODRÍGUEZ, J. L. (2012): Historiografía y líneas de investigación en historia de las universidades: Europa mediterránea e Iberoamérica. Miscelánea Alfonso IX, (Salamanca: Ediciones Universidad de Salamanca).

SANABRIA MUNÉVAR, F. (2010): Enseñando mutuamente: una aproximación al método lancasteriano y su apropiación en Colombia. (Institución educativa Francisco de Paula Santander), 13 (13), pp. 47-76.

SARRATE CAPDEVILLA, M. L. \&PÉREZ DE GUZMÁN, M. V. (2004): Educación de personas adultas, situación actual y propuestas de futuro. Revista de Educación, 336, pp. 41-57. 
SKOCPOL, T. \& SOMERS, M. (1980): The uses of comparative history in macrosocial inquiry. Comparative studies in society and history, 22 (2), pp.174-197.

TORRES AGUILAR, M. (2009): Extensión universitaria y universidades populares: el modelo de educación libre en la Universidad Popular mexicana (1912-1920). Revista historia de la educación latinoamericana, 12, pp. 196-219.

TIANA FERRER, A. (1991): La educación de adultos en el siglo XIX. Los primeros pasos hacia la constitución de un nuevo ámbito educativo. Revista de Educación, 294, pp. 7-26.

TIANA FERRER, A. y SANZ FERNÁNDEZ, F. (2003): Génesis y situación de la educación social en Europa. (Madrid: UNED)

TRETHEWEY, A. R. (1976): Introducing comparative education. (Exeter: Pergamon Press), pp.101-108.

UNESCO (2000): NFS Grundtvig, prospects: the quarterly review of comparative education. (Paris, UNESCO: International Bureau of Education), 23 (3 y 4), pp. 651-662.

\section{PROFESIOGRAFÍA}

\section{Victor M. Montes Martín}

Graduado en Pedagogía por la Universidad de Sevilla, estudios con los que recibí formación de diferentes temas. Entre los cuales se debe destacar en este caso la museológica, la cual fomentó estudios en relación a las Universidades Populares. Máster Universitario en Profesorado de ESO, Bachiller, FP y Enseñanzas de Idiomas, especializado en Formación y Orientación Laboral por la Escuela Universitaria de Osuna. Durante mis estudios de postgrado pude hacer uso de mis conocimientos en herramientas digitales. Colaborador independiente de diferentes grupos de investigación de la Universidad de Sevilla, donde pude desarrollar aptitudes en análisis de datos y estudiar sobre temas como redes sociales en el ámbito educativo y los sentimientos que producen las herramientas digitales en los alumnos de diferentes niveles. Fuera del ámbito académico he desarrollado labores de formador ocupacional y de enseñanza del ajedrez a niveles de educación primaria. Datos de contacto: Email: vmmm11pedagogo@gmail.com

Fecha de recepción: 28 de diciembre de 2015.

Fecha de aceptación: 18 de marzo de 2016. 